EXTENDED REPORT

\title{
Factors influencing visual acuity after intravitreal triamcinolone acetonide as treatment of exudative age related macular degeneration
}

\author{
J B Jonas, I Kreissig, R F Degenring
}

Br J Ophthalmol 2004;88:1557-1562. doi: 10.1136/bjo.2003.039552

See end of article for authors' affiliations .....................

Correspondence to: Dr J Jonas, UniversitätsAugenklinik, TheodorKutzer-Ufer 1-3, 68167 Mannheim, Germany; Jost.Jonas@ma.augen. uni-heidelberg.de

Accepted 1 February 2004
Aim: To evaluate factors influencing change in visual acuity (VA) after intravitreal injection of triamcinolone acetonide as treatment of exudative age related macular degeneration (AMD).

Methods: This prospective, interventional, comparative non-randomised clinical case series study included 94 patients (99 eyes) showing progressive exudative AMD with occult ( $n=61$ eyes), minimally classic $(n=18)$, predominantly classic $(n=1)$, or totally classic $(n=8)$ subfoveal neovascularisation. Mean follow up was 8.5 (SD 4.7) months (median, 7.3 months; range 3.1-24.5 months). All patients received an intravitreal injection of $20-25 \mathrm{mg}$ of triamcinolone acetonide.

Results: An increase in best VA of at least one line on the Snellen charts was found in $63(63.1 \%)$ eyes. Correspondingly, mean VA increased significantly $(p<0.001$ ) from 0.17 (SD 0.13 ) to 0.22 (SD 0.17 ) after the injection. Postoperative increase in VA was significantly $(p<0.001)$ and negatively correlated with preoperative VA (correlation coefficient, -0.49$)$. Gain in visual acuity was significantly $(p=0.009$ ) higher if preoperative visual acuity was less than 0.08 (gain: 3.2 (SD 2.9) Snellen lines) than if preoperative VA ranged between 0.08 and 0.20 (gain: 1.2 (SD 2.2) Snellen lines). Change in VA was significantly $(p=0.016)$ less if preoperative VA was higher than 0.20 (change: -0.8 (SD 3.4) Snellen lines). Maximal gain in VA was significantly $(p=0.035$ ) larger in eyes with retinal pigment epithelium detachment than in eyes with minimally classic subfoveal neovascularisation. This was statistically independent of age $(p=0.99)$, refractive error $(p=0.88)$, sex $(p=0.92)$, and duration of follow up $(p=0.46)$.

Conclusions: Gain in VA after intravitreal injection of 20-25 mg of triamcinolone acetonide is significantly and negatively correlated with preoperative VA. It is significantly larger in eyes with retinal pigment epithelium detachment than in eyes with minimally classic subfoveal neovascularisation.
1 ntravitreal triamcinolone acetonide has increasingly been used in previous studies as treatment for intraocular proliferative, oedematous, and neovascular diseases, such as diffuse diabetic macular oedema, ${ }^{1-3}$ proliferative diabetic retinopathy, ${ }^{4}$ neovascular glaucoma, ${ }^{5}$ central retinal vein occlusion, ${ }^{67}$ proliferative vitreoretinopathy, ${ }^{8}$ chronic prephthisical ocular hypotony, ${ }^{9}$ chronic uveitis, ${ }^{10-13}$ persistent pseudophakic cystoid macular oedema, ${ }^{14-16}$ and in other clinical situations. ${ }^{17}$ In aqueous humour and in silicone oil, triamcinolone acetonide has been found up to 1.5 years after the intravitreal injection. ${ }^{18-21}$ Systemic and local side effects reported so far include cataract, secondary ocular hypertension leading in some patients to secondary chronic open angle glaucoma, and post-injection infectious endophthalmitis. ${ }^{22-25}$

Due to its anti-oedematous and anti-angiogenic effects as shown in experimental investigations and clinical studies, ${ }^{26-42}$ intravitreal triamcinolone acetonide has additionally been used in previous pilot studies on exudative age related macular degeneration (AMD) in which some of the patients treated by intravitreal triamcinolone acetonide showed an increase in visual acuity after the injection. As it is important to know which patients may benefit from a treatment and which patients may not; the purpose of the present study was to evaluate which predictive factors are associated with a positive or negative response in terms of change in VA after the intravitreal injection of triamcinolone acetonide.

\section{PATIENTS AND METHODS}

Ninety four patients (61 women) (99 eyes; 49 right eyes) were included in the prospective clinical interventional case series study. These were all patients who showed neovascular AMD, who received an intravitreal injection of 20-25 mg of triamcinolone acetonide, for whom follow up was longer than three months, and who did not undergo cataract surgery in combination with, or after, the intravitreal injection. All patients were fully informed about the experimental character of the therapy. All patients had signed an informed consent. The study was performed at a university hospital. The ethics committee of the university had approved the study following the tenets of the Declaration of Helsinki.

Exclusion criterion was the predominantly classic or the totally classic type of subfoveal neovascularisation unless the patients were ineligible for photodynamic therapy. A subretinal haemorrhage should not have extended beyond the temporal vascular arcade. Additionally, patients with diabetic maculopathy, retinal vein occlusions, pseudophakic cystoid macular oedema, retinal telangiectasias, or other reasons for macular oedema were excluded from the study. History of glaucoma or of intraocular surgery including cataract surgery or retinal or vitreoretinal surgery were not exclusion criteria. None of the patients showed a marked progression of cataract. If cataract developed after the intravitreal injection and became a major vision reducing factor, cataract surgery was performed, and the patient was excluded from the study. Mean age was 77.9 (SD 7.2) years (median 78.4 years; range 58.0-100.1 years) and mean refractive error 0.85 (SD 2.01) diopters (median +0.88 diopters; range -7.00 diopters to

Abbreviations: $A M D$, age related macular degeneration; $V A$, visual acuity 
+5.88 diopters). Mean VA at baseline of the study was 0.17 (SD 0.13) (Snellen charts) (median 0.20; range, hand movement to 0.60 ), mean intraocular pressure measured 15.1 (SD 2.8) $\mathrm{mm} \mathrm{Hg}$ (median $16 \mathrm{~mm} \mathrm{Hg}$; range 8$24 \mathrm{~mm} \mathrm{Hg}$ ). For five patients, both eyes received an intravitreal injection of triamcinolone at an interval of 2 weeks to 11 months between the injections. Mean follow up time was 8.5 (SD 4.7) months (median 7.3 months; range 3.1-24.5 months).

Fluorescein angiogram performed for all patients showed an exudative AMD. The membrane was totally occult in 61 $(61.6 \%)$ eyes. In six $(9.8 \%)$ of the 61 eyes with occult subfoveal neovascularisation, a subfoveal haemorrhage was present, and in eight (13.1\%) eyes, a parafoveal subretinal haemorrhage was found. The subfoveal neovascularisation was minimally classic $(<50 \%)$ in $18(18.2 \%)$ eyes, of which in two $(11.1 \%)$ a subfoveal haemorrhage was present, and in four $(22.2 \%)$ a parafoveal subretinal haemorrhage was present. The subfoveal neovascularisation was predominantly classic $(>50 \%)$ in one $(1.0 \%)$ eye which did not show a subretinal haemorrhage. The subfoveal neovascularisation was totally classic $(>50 \%)$ in eight $(8.1 \%)$ eyes of which two $(25 \%)$ showed a subfoveal and parafoveal haemorrhage. A detachment of the retinal pigment epithelium was detected in $11(11.1 \%)$ eyes. For the patients with the predominantly classic type and the totally classic of subfoveal neovascularisation, photodynamic therapy had been recommended but was refused by the patients for various reasons such as cost and immobility.

The intravitreal injection of triamcinolone acetonide was performed under sterile conditions in the operation theatre using an operating microscope. Under topical anaesthesia, a paracentesis was performed to puncture the anterior chamber and to release some aqueous humour. After that, the patients received transconjunctivally an intravitreal injection of 20-25 mg of triamcinolone acetonide. The triamcinolone acetonide was usually prepared by the pharmacy by extracting $0.625 \mathrm{ml}$ from the ampoule (Volon A, Bristol-Myers-Squibb, Germany) containing $40 \mathrm{mg}$ of triamcinolone acetonide in $1 \mathrm{ml}$. The withdrawn volume was filled into a tuberculin syringe ( $1 \mathrm{ml}$ ) or a $2 \mathrm{ml}$ syringe. The syringe was filled up with Ringer's solution. A millipore filter (pore size, $5 \mu \mathrm{m}$; Sterifix Pury, Braun Melsungen AG, Melsungen, Germany) was placed on top of the syringe, and the content of the syringe was pressed through the filter with the triamcinolone acetonide crystals remaining in the syringe. The syringe was refilled with Ringer's solution, and the same procedure was repeated three times. At the end, $0.2 \mathrm{ml}$ of solution in the tuberculin syringe was left and, using a 27 gauge needle, the content was injected transconjunctivally into the vitreous cavity.

At baseline of the study and in repeated intervals afterwards, all patients underwent a routine ophthalmological examination including standardised VA measurement using Snellen charts, slit lamp biomicroscopy, Goldmann applanation tonometry, and ophthalmoscopy. The examinations were routinely performed at the first day after the injection, l week after the injection, 1 month after the injection, and at roughly monthly intervals from then on. Thirty three patients skipped at least one follow up examination within the first three months after the injection and returned for a later re-examination (table 1). For all patients included in the study, the results of at least one examination performed at least 3 months or more after the intravitreal injection were available.

For statistical analysis, the non-parametric Wilcoxon test was used to compare the changes in VA during the study period. To compare between the subgroups of the study, the Wilcoxon-Mann-Whitney test was applied.
Table 1 Visual acuity (VA) before and after an intravitreal injection of triamcinolone acetonide

\begin{tabular}{|c|c|c|c|c|}
\hline Time of examination & $\mathbf{n}$ & Mean VA (SD) & Median & p Value* \\
\hline Baseline & 99 & $0.17(0.13)$ & 0.20 & \\
\hline 1 week & 71 & $0.15(0.12)$ & 0.10 & 0.92 (NS) \\
\hline 1 month & 85 & $0.20(0.16)$ & 0.16 & 0.08 (NS) \\
\hline 2 months & 68 & $0.19(0.15)$ & 0.16 & 0.34 (NS) \\
\hline 3 months & 66 & $0.19(0.17)$ & 0.45 & 0.52 (NS) \\
\hline 4 months & 54 & $0.18(0.15)$ & 0.13 & 0.74 (NS) \\
\hline 5 months & 38 & $0.17(0.15)$ & 0.13 & 0.37 (NS) \\
\hline 6 months & 34 & $0.16(0.14)$ & 0.10 & 0.16 (NS) \\
\hline 7 months & 27 & $0.10(0.11)$ & 0.06 & 0.01 \\
\hline 8 months & 20 & $0.14(0.13)$ & 0.08 & 0.004 \\
\hline 9 months & 15 & $0.12(0.11)$ & 0.08 & 0.04 \\
\hline 10 months & 7 & $0.06(0.03)$ & 0.05 & 0.18 (NS) \\
\hline $\begin{array}{l}11 \text { months } \\
\text { After injection }\end{array}$ & 16 & $0.12(0.09)$ & 0.08 & 0.02 \\
\hline Maximum & 99 & $0.22(0.17)$ & 0.16 & $<0.001$ \\
\hline $\begin{array}{l}\text { Maximum gain in } \\
\text { Snellen lines }\end{array}$ & 99 & & & \\
\hline
\end{tabular}

*Significance of differences between the baseline before injection. NS, not significant.

\section{RESULTS}

After the injection, mean VA significantly $(p<0.001)$ increased from 0.17 (SD 0.13) (median 0.20; range, hand movements to 0.60 ) to a maximum of 0.22 (SD 0.17) (median 0.16; range 0.02-0.90). The increase in VA was statistically marginally significant for the measurement taken at 1 month after the injection $(p=0.08)$ (table 1$)$. Comparing preoperative VA with the best postoperative VA and expressing VA in Snellen lines, 17 (17.2\%) eyes lost at least one Snellen line in VA, and $63(63.6 \%)$ eyes gained at least one Snellen line in VA (fig 1 ). Nine $(9.1 \%$ ) eyes showed a loss of at least three lines, and $27(27.3 \%)$ eyes showed an improvement of at least three lines (fig 1). Considering VA taken at three months after the injection, 12 (18.2\%) out of 66 eyes showed a loss in VA of at least three lines, and 13 $(19.7 \%)$ eyes showed an increase in VA by at least three lines (fig 2). After a follow up of 6 months, 14 (41.2\%) out of 34 eyes showed a loss in VA of at least three lines, and five (14.7\%) eyes showed an increase in VA by at least three lines (fig 3).

Taking the entire study group, post-injection VA was significantly and negatively correlated with preoperative VA (fig 4; tables 2-4). The less the preoperative VA was, the

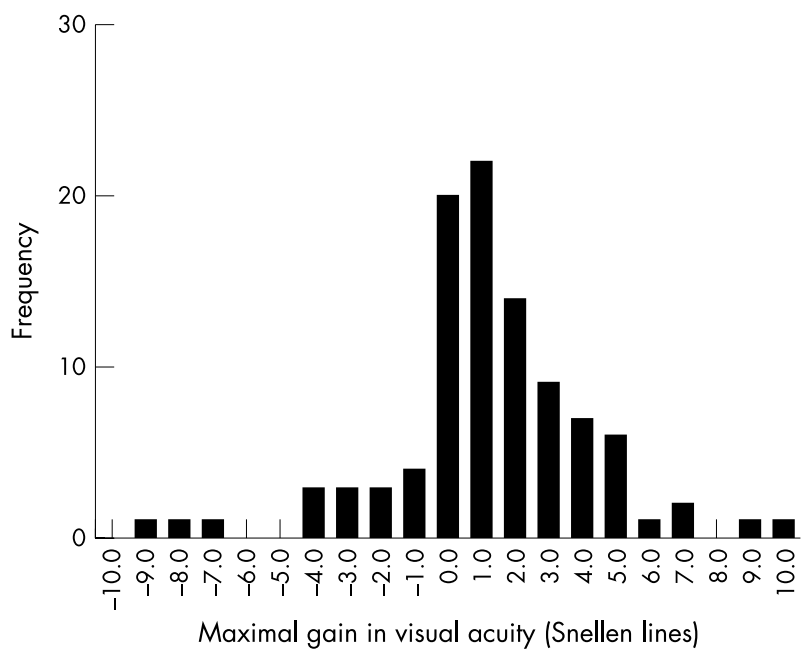

Figure 1 Histogram showing the distribution of the post-injection maximal gain in visual acuity expressed in Snellen lines. 


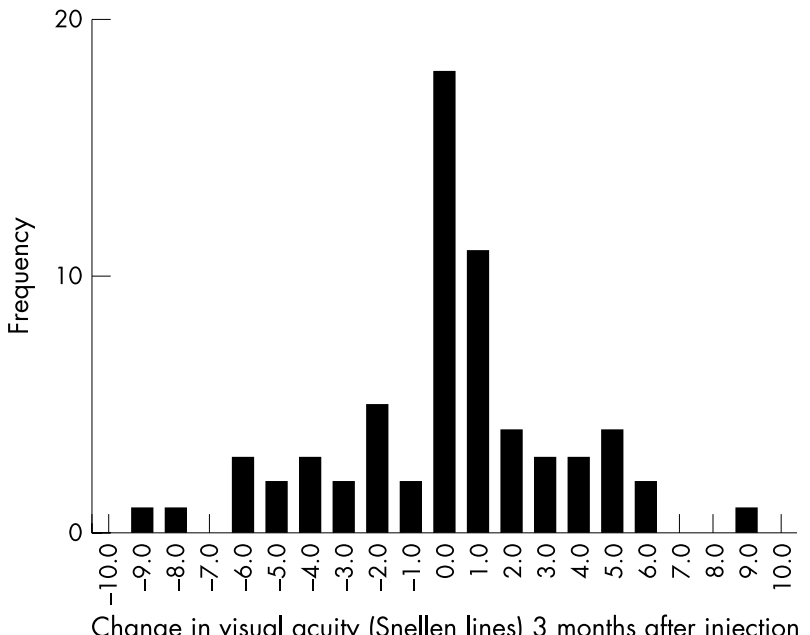

Figure 2 Histogram showing the distribution of the gain in visual acuity (Snellen lines) 3 months after an injection of triamcinolone acetonide.

higher the maximal gain in VA was after the injection. Correspondingly, the maximal gain in VA expressed in Snellen lines, was significantly $(p=0.009)$ higher for eyes with a preoperative VA of less than 0.08 (gain: 3.2 (SD 2.9) Snellen lines) than for eyes with a preoperative VA of higher than 0.08 and less than, or equal to, 0.20 (gain: 1.2 (SD 2.2) Snellen lines). Change in VA was significantly $(\mathrm{p}=0.016)$ lowest if preoperative VA was higher than 0.20 (change: -0.8 (SD 3.4) Snellen lines).

The maximal gain in VA was statistically independent of age $(p=0.99)$, refractive error $(p=0.88)$, right or left eye $(p=0.46)$, sex $(p=0.92)$, and duration of follow up $(\mathrm{p}=0.46)$.

Dividing the whole study group into subgroups according to the type of subfoveal neovascularisation, maximal gain in VA after the intravitreal injection was significantly larger in the subgroup with retinal pigment epithelium detachment than in the subgroup with minimally classic subfoveal neovascularisation $(\mathrm{p}=0.035)$ (table 5$)$. For the totally classic and totally occult type of subfoveal neovascularisation, the differences were statistically not significant $(p>0.20)$ (table 5). For all subgroups except for the subgroup with predominantly classic subfoveal neovascularisation $(\mathrm{n}=\mathrm{l}$

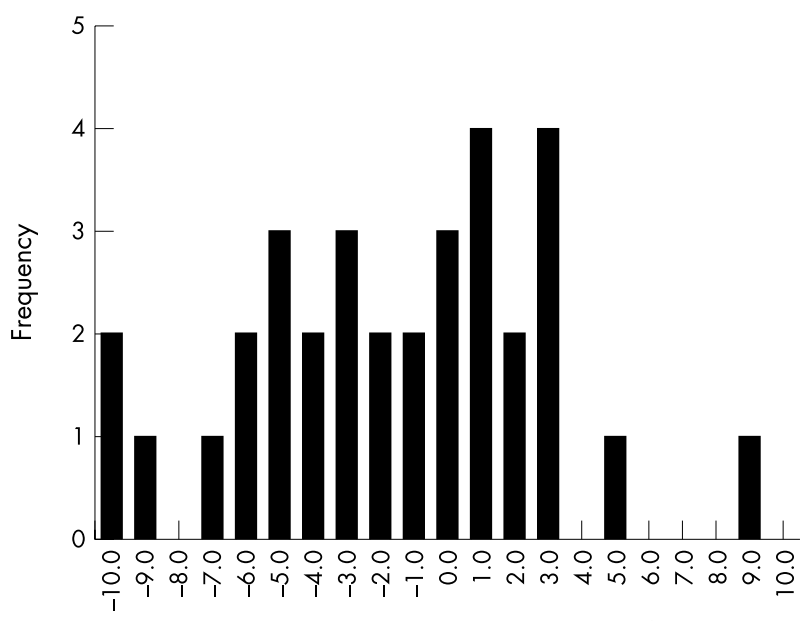

Gain in visual acuity (Snellen lines) 6 months after injection

Figure 3 Histogram showing the distribution of the gain in visual acuity (Snellen lines) 6 months after an injection of triamcinolone acetonide.

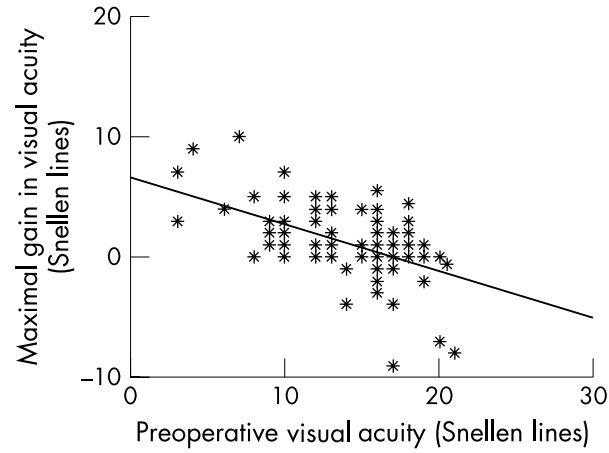

Figure 4 Scattergram showing the correlation between preoperative visual and maximal gain in visual acuity after an injection of triamcinolone acetonide. Correlation coefficient $-0.49 ; \mathrm{p}<0.001$.

eye), the correlation between gain in VA after the injection and preoperative VA was significant $(\mathrm{p}<0.05)$.

Dividing the entire study group into eyes with a steroid induced ocular hypertension developing in 46 (46.5\%) eyes, and into eyes with a maximal intraocular pressure of $21 \mathrm{~mm} \mathrm{Hg}$ or less after the injection, did not show a

Table 2 Visual acuity (VA) before and after an intravitreal injection of triamcinolone acetonide in eyes with a preoperative VA of less than 0.08

\begin{tabular}{lrlll}
\hline Time of examination & $\mathbf{n}$ & Mean VA (SD) & Median & p Value* \\
\hline Baseline & 23 & $0.04(0.02)$ & 0.04 & \\
1 week & 21 & $0.07(0.06)$ & 0.05 & 0.10 (NS) \\
1 month & 19 & $0.08(0.06)$ & 0.06 & 0.001 \\
2 months & 15 & $0.06(0.06)$ & 0.04 & 0.15 (NS) \\
3 months & 13 & $0.08(0.06)$ & 0.05 & 0.008 \\
4 months & 10 & $0.07(0.06)$ & 0.04 & 0.089 (NS) \\
5 months & 9 & $0.07(0.06)$ & 0.06 & 0.075 (NS) \\
6 months & 5 & $0.09(0.06)$ & 0.07 & 0.04 \\
7 months & 7 & $0.04(0.02)$ & 0.04 & 0.068 (NS) \\
8 months & 5 & $0.09(0.09)$ & 0.05 & 0.066 (NS) \\
Affer injection & & & & \\
Maximum & 23 & $0.08(0.06)$ & 0.06 & $<0.001$ \\
Maximum gain in & 23 & $3.2(2.9)$ & & \\
Snellen lines & & & & \\
\end{tabular}

*Significance of differences between the baseline prior to the injection. NS, not significant.

Table 3 Visual acuity (VA) before and after an intravitreal injection of triamcinolone acetonide in eyes with a preoperative VA of higher than 0.08 and less than, or equal to, 0.20

\begin{tabular}{lrlll}
\hline Time of examination & $\mathbf{n}$ & Mean VA (SD) & Median & p Value* \\
\hline Baseline & 52 & $0.16(0.05)$ & 0.20 & \\
1 week & 40 & $0.16(0.11)$ & 0.14 & $0.75(\mathrm{NS})$ \\
1 month & 46 & $0.19(0.13)$ & 0.16 & $0.11(\mathrm{NS})$ \\
2 months & 36 & $0.18(0.13)$ & 0.11 & $0.40(\mathrm{NS})$ \\
3 months & 39 & $0.17(0.14)$ & 0.13 & $0.62(\mathrm{NS})$ \\
4 months & 30 & $0.16(0.13)$ & 0.10 & $0.86(\mathrm{NS})$ \\
5 months & 20 & $0.15(0.10)$ & 0.13 & $0.62(\mathrm{NS})$ \\
6 months & 18 & $0.15(0.12)$ & 0.08 & $0.91(\mathrm{NS})$ \\
7 months & 13 & $0.12(0.14)$ & 0.08 & 0.31 (NS) \\
8 months & 8 & $0.11(0.12)$ & 0.08 & 0.49 (NS) \\
After injection & & & & \\
Maximum & 23 & $0.22(0.13)$ & 0.20 & $<0.001$ \\
Maximum gain in & 52 & $1.2(2.2)$ & & \\
Snellen lines & & & & \\
\end{tabular}

*Significance of differences between the baseline prior to the injection. NS, not significant. 
Table 4 Visual acuity (VA) before and after an intravitreal injection of triamcinolone acetonide in eyes with a preoperative VA of higher than 0.20

\begin{tabular}{lrlll}
\hline Time of examination & $\mathbf{n}$ & Mean VA (SD) & Median & $\mathbf{p}$ Value \\
\hline Baseline & 24 & $0.35(0.11)$ & 0.30 & \\
1 week & 10 & $0.28(0.13)$ & 0.30 & 0.10 (NS) \\
1 month & 20 & $0.32(0.18)$ & 0.30 & 0.39 (NS) \\
2 months & 17 & $0.32(0.17)$ & 0.30 & 0.78 (NS) \\
3 months & 14 & $0.32(0.23)$ & 0.30 & $0.45(\mathrm{NS})$ \\
4 months & 14 & $0.30(0.17)$ & 0.30 & $0.30(\mathrm{NS})$ \\
5 months & 9 & $0.30(0.22)$ & 0.20 & $0.16(\mathrm{NS})$ \\
6 months & 11 & $0.20(0.18)$ & 0.13 & 0.05 \\
7 months & 7 & $0.12(0.09)$ & 0.10 & 0.02 \\
8 months & 7 & $0.20(0.12)$ & 0.20 & 0.02 \\
After injection & & & & \\
Maximum & 23 & $0.35(0.20)$ & 0.35 & 0.97 (NS) \\
Maximum gain in & 24 & $-0.8(3.4)$ & & \\
Snellen lines & & & & \\
\end{tabular}

*Significance of differences between the baseline prior to the injection. NS, not significant.

statistically significant $(p>0.20)$ difference in gain in VA after the injection between the two study subgroups.

\section{DISCUSSION}

For patients with exudative AMD, recent investigations have proved that photodynamic therapy is of benefit in the treatment of the classic type of subfoveal neovascularisation. ${ }^{43-45}$ Treatment of exudative AMD with minimally classic subfoveal neovascularisation, however, has been inconclusive so far because studies have not shown a marked therapeutic effect of photodynamic therapy. Consequently, other treatment modalities have been investigated of which one is the intravitreal application of triamcinolone acetonide. Gillies and colleagues, who injected $4 \mathrm{mg}$ of triamcinolone acetonide intravitreally, did not find a pronounced effect of intravitreal triamcinolone acetonide on VA. ${ }^{46}$ Danis and colleagues performed a comparative study and reported a beneficial effect of $4 \mathrm{mg}$ of triamcinolone acetonide in their study group compared with the control group. ${ }^{31}$ A recent investigation including 71 eyes with exudative AMD showed a significant increase in VA after an intravitreal injection of 20-25 mg of triamcinolone acetonide..$^{41}$ The improvement in VA was significant for the examinations performed 1 month $(\mathrm{p}=0.04)$ and 2 months $(\mathrm{p}=0.04)$ after the injection. About 3-5 months after the injection, VA declined so that VA measurements obtained at the end of the follow up period of that study did not differ significantly $(p=0.17)$ from the baseline values. Overall, 48 (66.2\%) eyes gained in VA during the follow up period..$^{41}$
Based on these preceding studies, the purpose of the present investigation was to evaluate which factors may be associated with an increase or decrease of VA after an intravitreal injection of triamcinolone acetonide in patients with exudative AMD. Preoperative VA significantly influenced VA after the injection. Patients with a relatively high preoperative VA showed a more pronounced loss of VA than patients with a relative low preoperative VA (tables 2-4; fig 4). It suggests that for eyes with a preoperative VA of less than 0.20, intravitreal injection of triamcinolone acetonide can result in an increase in VA. Eyes with a preoperative VA of higher than 0.20 may loose VA after the injection. It does, however, not necessarily mean that the loss in VA after the intravitreal injection is caused by the intravitreal injection itself. It may be that the eyes with loss in VA after the injection would have lost more in VA if the intravitreal injection had not been performed.

The type of subfoveal neovascularisation was another factor influencing gain in VA after the intravitreal injection. Eyes with a detachment of the retinal pigment epithelium showed a significantly higher increase in VA than eyes with a minimally classic subfoveal neovascularisation in which VA did not markedly change after the intravitreal injection (table 5). It may have clinical importance, as photodynamic therapy has not been shown to increase VA in patients with retinal pigment epithelium detachment.

There are limitations of the present study, one of which is the design as a non-randomised case series investigation. As it was not the purpose of the study to examine whether intravitreal triamcinolone has a therapeutically beneficial effect on VA but to evaluate which factors are associated with a positive or negative change in VA after the intravitreal injection, a randomised prospective study design may not have been necessary. Another limitation may be that, although intravitreal triamcinolone will have increased cataract, cataract surgery was not performed in combination with, or after the intravitreal injection. The vision reducing effect of progressive cataract, however, may have hidden parts of a vision improving effect of triamcinolone so that this limitation of the study may serve to support the conclusion of the investigation. An additional limitation of the study may be the relatively high dosage of triamcinolone acetonide injected into the eye. In all preceding studies of other study centres applying intravitreal triamcinolone acetonide as treatment of exudative AMD, a dosage of $4 \mathrm{mg}$ was used. $^{313246}$ We chose to use $20-25 \mathrm{mg}$ of triamcinolone acetonide because, from the very beginning of our ongoing triamcinolone investigations (now involving more than 400 patients with various diseases), we have used the same dosage of 20-25 mg triamcinolone acetonide and have not seen yet the side effects normally attributed to that high dosage. An additional reason for the high dosage in the

\begin{tabular}{|c|c|c|c|c|c|c|c|}
\hline \multirow[b]{2}{*}{$\begin{array}{l}\text { Type of subretinal } \\
\text { neovascularisation }\end{array}$} & \multirow[b]{2}{*}{$\mathbf{n}$} & \multicolumn{6}{|c|}{ Visual acuity change } \\
\hline & & $\begin{array}{l}\text { Snellen value, } \\
\text { mean (SD) }\end{array}$ & Median & Range & $\begin{array}{l}\text { Snellen lines, } \\
\text { mean (SD) }\end{array}$ & Median & Range \\
\hline $\begin{array}{l}\text { Retinal pigment } \\
\text { epithelium } \\
\text { detachment }\end{array}$ & 11 & $0.17(0.21)$ & 0.05 & 0.00 to 0.60 & $2.3(2.3)$ & 1.0 & 0 to 5.5 \\
\hline Totally classic type & 8 & $0.04(0.10)$ & 0.03 & -0.10 to 0.17 & $1.8(4.3)$ & 1.5 & -4 to 9 \\
\hline Totally occult type & 61 & $0.05(0.12)$ & 0.04 & -0.50 to 0.30 & $1.2(2.9)$ & 1.0 & -9 to 10 \\
\hline $\begin{array}{l}\text { Minimally classic } \\
\text { type }\end{array}$ & 18 & $-0.02(0.14)$ & 0.01 & -0.40 to 0.30 & $0.1(3.1)$ & 0.5 & -7 to 5 \\
\hline $\begin{array}{l}\text { Predominantly } \\
\text { classic type }\end{array}$ & 1 & 0.01 & 1 & & & & \\
\hline
\end{tabular}


present study was that in preceding studies on the intravitreal use of $4 \mathrm{mg}$ of triamcinolone acetonide for patients with exudative AMD, the therapeutic effect has not been quite clear. ${ }^{46}$

In several preceding studies, a single intravitreal injection of triamcinolone acetonide has already been used as treatment for exudative AMD. In 1998, Challa et al ${ }^{32}$ evaluated safety and efficacy of intravitreal triamcinolone after 18 months of follow up in patients with exudative AMD considered unsuitable for laser photocoagulation. In the nonrandomised clinical pilot study, 30 eyes of 28 patients were treated with an intravitreal injection of triamcinolone $(4 \mathrm{mg})$. Of the 20 eyes with initial VA of 0.10 or better, vision was maintained in 11 eyes $(55 \%)$, and six eyes $(30 \%)$ suffered severe visual loss (six or more lines). VA improved in three of 10 eyes with initial vision of $3 / 60$ or worse. The authors concluded that a single intravitreal injection of $4 \mathrm{mg}$ triamcinolone may be reasonably well tolerated and may be helpful in the treatment of exudative AMD. In a randomised clinical trial, Danis and colleagues examined the effects of intravitreal injection of $4 \mathrm{mg}$ triamcinolone acetonide on the visual and clinical course of exudative AMD in 27 patients who were compared with a non-treated control group. ${ }^{33}$ The authors found that VA was significantly $(p<0.005)$ better in the treated group compared with control subjects at 3 and 6 months follow up. An increase in intraocular pressure was seen in $25 \%$ of treated patients, but was controlled with topical medications. Progression of cataract was more frequently detected in the treated group. The authors concluded that intravitreal triamcinolone acetonide may provide improvement in VA in exudative AMD. These clinical studies were supported by experimental studies on the effect of intravitreal cortisone on experimental subretinal neovascularisation and other types of intraocular blood vessel proliferation. ${ }^{26-29}$ The results of the present study and of the other investigations mentioned above are partially in contrast to a recent study by Gillies and colleagues, who found no effect of $4 \mathrm{mg}$ of intravitreal triamcinolone acetonide on the development of severe visual loss over a follow up period of one year. ${ }^{46}$ One of the reasons for the discrepancy between the investigation performed by Gillies and colleagues and the present study may be the difference in the dosage of triamcinolone acetonide injected. Another reason may be that in the study by Gillies and colleagues, re-injections were not performed. At the end of the follow up, VA was no longer better than before the intravitreal injection. Interestingly, Gillies et al found a statistically significant and therapeutically positive effect of intravitreal triamcinolone on the size of the subfoveal neovascularisation 3 months after the injection. It is in agreement with experimental studies on an angiostatic effect of intravitreal cortisone on experimental subretinal neovascularisation and other types of intraocular blood vessel proliferation. ${ }^{26-29}$ An additional reason for the discrepancy between the study by Gillies et al and the present and other preceding studies may be that Gillies' investigation included patients with the classic type of subfoveal neovascularisation which is associated with a worse prognosis compared with the occult type. The most recent study on the intravitreal use of triamcinolone acetonide in eyes with exudative AMD was reported by Spaide and colleagues who combined photodynamic therapy with intravitreal triamcinolone acetonide and found an unexpectedly low frequency of photodynamic retreatments as compared with data in the literature. ${ }^{47}$

In conclusion, the data of the present pilot study suggest that the gain in VA after an intravitreal injection of $20-25 \mathrm{mg}$ of triamcinolone acetonide in patients with exudative AMD is significantly better in eyes with low preoperative acuity than in eyes with high preoperative VA, and that the gain in VA may be higher for eyes with retinal pigment detachment than in eyes with minimally classic subfoveal neovascularisation.

\section{Authors' affiliations}

J B Jonas, I Kreissig, R F Degenring, Department of Ophthalmology, Faculty of Clinical Medicine Mannheim of the University Heidelberg, Germany

Proprietary interest: none

\section{REFERENCES}

1 Jonas JB, Söfker A. Intraocular injection of crystalline cortisone as adjunctive treatment of diabetic macular oedema. Am J Ophthalmol 2001;132:425-7.

2 Martidis A, Duker JS, Greenberg PB, et al. Intravitreal triamcinolone for refractory diabetic macular edema. Ophthalmology 2002; 109:920-7.

3 Jonas JB, Kreissig I, Söfker A, et al. Intravitreal injection of triamcinolone acetonide for diabetic macular edema. Arch Ophthalmol 2003;121:57-61.

4 Jonas JB, Hayler JK, Söfker A, et al. Intravitreal injection of crystalline cortisone as adjunctive treatment of proliferative diabetic retinopathy. Am J Ophthalmol 2001;131:468-71.

5 Jonas JB, Hayler JK, Söfker A, et al. Regression of neovascular iris vessels by intravitreal injection of crystalline cortisone. J Glaucoma $2001 ; 10: 284-7$.

6 Greenberg PB, Martidis A, Rogers AH, et al. Intravitreal triamcinolone acetonide for macular oedema due to central retinal vein occlusion. Br J Ophthalmol 2002;86:247-8.

7 Jonas JB, Kreissig I, Degenring RF. Intravitreal triamcinolone acetonide as treatment of macular edema in central retinal vein occlusion. Graef Arch Clin Exp Ophthalmol 2002;240:782-3.

8 Jonas JB, Hayler JK, Panda-Jonas S. Intravitreal injection of crystalline cortisone as adjunctive treatment of proliferative vitreoretinopathy. Br J Ophthalmol 2000;84:1064-7.

9 Jonas JB, Hayler JK, Panda-Jonas S. Intravitreal injection of crystalline cortisone as treatment of pre-phthisical ocular hypotony. Graef Arch Clin Exp Ophthalmol 2001;239:464-5.

10 Antcliff RJ, Spalton DJ, Stanford MR, et al. Intravitreal triamcinolone for uveitic cystoid macular edema: an optical coherence tomography study. Ophthalmology 2001;108:765-72.

11 Martidis A, Duker JS, Puliafito CA. Intravitreal triamcinolone for refractory cystoid macular edema secondary to birdshot retinochoroidopathy. Arch Ophthalmol 2001;119:1380-3.

12 Young S, Larkin G, Branley M, et al. Safety and efficacy of intravitreal triamcinolone for cystoid macular oedema in uveitis. Clin Experiment Ophthalmol $2001 ; 29: 2-6$.

13 Degenring RF, Jonas JB. Intravitreal injection of triamcinolone acetonide as treatment of chronic uveitis. Br J Ophthalmol 2003;87:361.

14 Benhamou N, Massin P, Haouchine B, et al. Intravitreal triamcinolone for refractory pseudophakic macular edema. Am J Ophthalmol 2003; 135:246-9

15 Conway MD, Canakis C, Livir-Rallatos C, et al. Intravitreal triamcinolone acetonide for refractory chronic pseudophakic cystoid macular edema. $J$ Cataract Refract Surg 2003;29:27-33.

16 Jonas JB, Kreissig I, Degenring RF. Intravitreal triamcinolone acetonide for pseudophakic cystoid macular edema. Am J Ophthalmol 2003;136:384-6.

17 Peyman GA, Cheema R, Conway MD, et al. Triamcinolone acetonide as an aid to visualization of the vitreous and the posterior hyaloid during pars plana vitrectomy. Retina 2000;20:554-5.

18 Jonas JB. Concentration of intravitreally applicated triamcinolone acetonide in aqueous humour. Br J Ophthalmol 2002;86:1066.

19 Jonas JB. Concentration of intravitreally injected triamcinolone acetonide in intraocular silicone oil. Br J Ophthalmol 2002;86:1450-1.

20 Beer PM, Bakri SJ, Singh RJ, et al. Intraocular concentration and pharmacokinetics of triamcinolone acetonide after a single intravitreal injection. Ophthalmology 2003;110:681-6.

21 Jonas JB. Intraocular availability of triamcinolone acetonide after intravitreal injection. Am J Ophthalmol 2004;137:560-2.

22 Wingate RJ, Beaumont PE. Intravitreal triamcinolone and elevated intraocular pressure. Aust N Z J Ophthalmol 1999;27:431-2.

23 Jonas JB, Kreissig I, Degenring R. Intraocular pressure after intravitrea injection of triamcinolone acetonide. Br J Ophthalmol 2003;87:24-7.

24 Benz MS, Murray TG, Dubovy SR, et al. Endophthalmitis caused by Mycobacterium chelonae abscessus after intravitreal injection of triamcinolone. Arch Ophthalmol 2003;121:271-3.

25 Sutter FK, Gillies MC. Pseudo-endophthalmitis after intravitreal injection of triamcinolone. Br J Ophthalmol 2003;87:972-4.

26 Tano Y, Sugita G, Abrams G, et al. Inhibition of intraocular proliferation with intravitreal corticosteroid. Am J Ophthalmol 1980;89:131-6.

27 Tano Y, Chandler D, Machemer R. Treatment of intraocular proliferation with intravitreal injection of tramcinolone acetonide. Am J Ophthalmol 1980;90:810-16.

28 Ishibashi T, Miki K, Sorgente N, et al. Effects of intravitreal administration of steroids on experimental subretinal neovascularization in the subhuman primate. Arch Ophthalmol 1985;103:708-11.

29 Antoszyk AN, Gottlieb JL, Machemer R, et al. The effects of intravitreal triamcinolone acetonide on experimental pre-retinal neovascularization. Graefes Arch Clin Exp Ophthalmol 1993;231:34-40 
30 Penfold PL, Gyory JF, Hunyor AB, et al. Exudative macular degeneration and intravitreal triamcinolone. A pilot study. Aust N Z J Ophthalmol 1995;23:293-8.

31 Danis RP, Bingaman DP, Yang Y, et al. Inhibition of preretinal and optic nerve head neovascularization in pigs by intravitreal triamcinolone acetonide. Ophthalmology 1996;103:2099-104.

32 Challa JK, Gillies MC, Penfold PL, et al. Exudative macular degeneration and intravitreal triamcinolone: 18 month follow up. Aust N Z J Ophthalmol 1998;26:277-81.

33 Danis RP, Ciulla TA, Pratt $L M$, et al. Intravitreal triamcinolone acetonide in exudative age-related macular degeneration. Retina 2000;20:244-50.

34 Penfold PL, Wen L, Madigan MC et al. Modulation of permeability and adhesion molecule expression by human choroidal endothelial cells. Invest Ophthalmol Vis Sci 2002;43:3125-30.

35 Jonas JB, Kreissig I, Degenring RF. Repeated intravitreal injections of triamcinolone acetonide as treatment of progressive exudative age-related macular degeneration. Graef Arch Clin Exp Ophthalmol 2002;240:873-4.

36 Penfold PL. Intravitreal triamcinolone in recurrence of choroidal neovascularisation. Br J Ophthalmol 2002;86:600-1.

37 Penfold PL, Wong JG, Gyory J, et al. Effects of triamcinolone acetonide on microglial morphology and quantitative expression of MHC-II in exudative age-related macular degeneration. Clin Experiment Ophthalmol 2001;29:188-92

38 Ciulla TA, Criswell MH, Danis RP, et al. Intravitreal triamcinolone acetonide inhibits choroidal neovascularization in a laser-treated rat model. Arch Ophthalmol 2001;119:399-404.

39 Penn JS, Rajaratnam VS, Collier RJ, et al. The effect of an angiostatic steroid on neovascularization in a rat model of retinopathy of prematurity. Invest Ophthalmol Vis Sci 2001;42:283-90.
40 Ranson NT, Danis RP, Ciulla TA, et al. Intravitreal triamcinolone in subfoveal recurrence of choroidal neovascularisation after laser treatment in macular degeneration. Br J Ophthalmol 2002;86:527-9.

41 Jonas JB, Kreissig I, Hugger $\mathrm{P}$, et al. Intravitreal triamcinolone acetonide for exudative age-related macular degeneration. $\mathrm{Br} J$ Ophthalmol 2003;87:462-8.

42 Spaide RF, Sorenson J, Maranan L. Combined photodynamic therapy with verteporfin and intravitreal triamcinolone acetonide for choroidal neovascularization. Ophthalmology 2003;110:1517-25.

43 Schmidt-Erfurth U, Miller JW, Sickenberg M, et al. Photodynamic therapy with verteporfin for choroidal neovascularization caused by age-related macular degeneration: results of retreatments in a phase 1 and 2 study. Arch Ophthalmol 1999;117:1177-87.

44 Treatment of age-related macular degeneration with photodynamic therapy (TAP) Study Group. Photodynamic therapy of subfoveal choroidal neovascularization in age-related macular degeneration with verteporfin: one-year results of 2 randomized clinical trials-TAP report. Arch Ophthalmol 1999;117:1329-45.

45 Bressler NM. Treatment of Age-Related Macular Degeneration with Photodynamic Therapy (TAP) Study Group. Photodynamic therapy of subfoveal choroidal neovascularization in age-related macular degeneration with verteporfin: two-year results of 2 randomized clinical trials-tap report 2 . Arch Ophthalmol 2001;119:198-207.

46 Gillies MC, Simpson JM, Luo W, et al. A randomized clinical trial of a single dose of intravitreal triamcinolone acetonide for neovascular age-related macular degeneration: one-year results. Arch Ophthalmol 2003;121:667-73

47 Spaide RF, Sorenson J, Maranan L. Combined photodynamic therapy with verteporfin and intravitreal triamcinolone acetonide for choroidal neovascularization. Ophthalmology 2003;110:1517-25. 